\title{
Pemetaan Permasalahan BMT (Baitul Mal Wat Tamwil): Pendekatan Teori Manajemen Strategi Environmental Scaning
}

\author{
Wijiharta \\ STEI Hamfara Yogyakarta \\ Email: wijiharta@steihamfara.ac.id
}

\begin{abstract}
Abstrak:
Baitul Mal wat Tamwil (BMT) is a sharia microfinance institution in Indonesia. The presence of BMTs, like microfinance institutions in various countries, is quite helpful for small communities. Various problems according to some previous researchers still cover BMT. This study aims to map various BMT problems with the approach of management strategy theory, especially environmental scanning. This type of research is qualitative and descriptive. Data sources used are secondary data sources in the form of documents. Documents are limited to textbooks and scientific journals with certain categories. Stages of qualitative research analysis include data collection, reduction, presentation and conclusion - verification. This study concludes that problem mapping of BMT can use an environmental scanning management strategy theory approach. The results of the BMT problem mapping: BMT internal environmental problems are in HR and service product concepts, industrial environment problems are in the bargaining power of consumers / customers (community acceptance), and BMT macro environment issues are in legislation and regulation.

[Baitul Mal wat Tamwil (BMT) adalah suatu lembaga keuangan mikro syariah di Indonesia. Kehadiran BMT, sebagaimana lembaga keuangan mikro di berbagai negara, cukup membantu bagi masyarakat kecil. Berbagai permasalahan menurut beberapa peneliti sebelumnya masih menyelimuti BMT. Penelitian ini bertujuan untuk memetakan berbagai permasalahan BMT tersebut dengan pendekatan teori manajemen strategi khususnya environmental scaning. Jenis penelitian ini adalah kualitatif dan bersifat deksriptif. Sumber data yang digunakan adalah sumber data sekunder berupa dokumen. Dokumen dibatasi berupa buku teks (textbook) dan jurnal ilmiah dengan kategori tertentu. Tahapan analisa penelitian kualitatif meliputi koleksi data, reduksi, penyajian dan konklusi -verifikasi. Penelitian ini menghasilkan kesimpulan bahwa pemetaan permasalahan BMT bisa menggunakan pendekatan teori environmental scanning manajemen strategi. Hasil pemetaan permasalahan BMT: permasalahan lingkungan internal BMT adalah pada SDM dan konsep produk jasa, permasalahan lingkungan industri adalah pada daya tawar konsumen/nasabah.]
\end{abstract}

Kata Kunci: Baitul Mal wat Tamwil (BMT); Pemetaan Masalah; Manajemen Strategi. 
Wijiharta

\section{PENDAHULUAN}

Lembaga keuangan mikro (microfinance institutions) di berbagai negara berperan penting dalam memberikan layanan keuangan bagi masyarakat kelas bawah. ${ }^{1}$ Terdapat dua model lembaga keuangan mikro, yaitu lembaga keuangan mikro konvensional dan lembaga keuangan mikro syariah (Islamic microfinance institutions). ${ }^{2}$ Bentuk lembaga keuangan mikro syariah di Indonesia dikenal masyarakat sebagai BMT (Baitul Mal wat Tamwil). ${ }^{3}$

Kehadiran BMT di Indonesia telah dirasakan manfaatnya oleh masyarakat kecil, khususnya yang tidak bankable dan menolak riba. ${ }^{4}$ Kiprah BMT di masyarakat tersebut telah menjadikan BMT berperan strategis. ${ }^{5}$ Peran BMT cukup signifikan dan sentral dalam memberi akses permodalan bagi usaha mikro-kecil, ${ }^{6}$ sekaligus sebagai upaya pengentasan kemiskinan. ${ }^{7}$

Fakta adanya BMT yang tumbuh dan berkembang, akan tetapi pada sisi lain ada pula yang jatuh dan gagal, mengindikasikan bahwa ada permasalahan yang melingkupi BMT. ${ }^{8}$ Beberapa peneliti telah mengemukakan berbagai pendapat mengenai berbagai permasalahan yang melingkupi BMT. Permasalahan tersebut diantaranya adalah menyangkut sumberdaya manusia, ${ }^{9}$ permodalan ${ }^{10}$ hingga kelembagaan..$^{11}$

Berbagai permasalahan yang telah dikemukakan para peneliti tersebut menggambarkan kompleksnya permasalahan yang melingkupi BMT. Beberapa penelitian terkait permasalahan BMT belum menekankan pada pemetaan permasalahan dengan berbasis suatu teori, sehingga masih merupakan inventarisasi berbagai permasalahan untuk kemudian diteliti secara parsial. Pemetaan permasalahan BMT secara sistematis agar bisa dipahami permasalahannya secara komprehensif. Belum dijumpai penelitian yang fokus

\footnotetext{
1 Liñares-zegarra \& Wilson, "The size and growth of microfinance institutions", The British Accounting Review, (2017).

2 Mobin, Masih, \& Alhabshi, : Religion of Islam and Microfinance: Does It Make Any Difference?, Emerging Markets Finance and Trade, (2017).

3 Wulandari, P. et.al., "Unique aspects of Islamic microfinance financing process: experience of Baitul Maal Wa Tamwil in Indonesia", Humanomics, Vol. 32 Iss 3, (2016),

4 Masyithoh ANALISIS NORMATIF UNDANG-UNDANG NO. 1 TAHUN 2013 TENTANG LEMBAGA KEUANGAN MIKRO (LKM) ATAS STATUS BADAN HUKUM DAN PENGAWASAN BAITUL MAAL WAT TAMWIL (BMT). Economica Jurnal Ekonomi Islam, V(1), (2013) : 17-36.

5 Apriadi, F., \& Findi A, M., Solusi Peningkatan Sumberdaya Manusia Pada Baytul Maal wat Tamwil ( BMT ) di Indonesia Melalui Pendekatan Analytic Network Process ( ANP) The Solution of Human Resources Development for Baytul Maal wat Tamwil ( BMT ) in Indonesia : an Analytic Network Pr. Jurnal Al-Muzara'ah, 1(2), (2013) : 107118

6 Sakti, A., PEMETAAN KONDISI DAN POTENSI BMT : Kemitraan dalam rangka Memperluas Pasar \& Jangkauan Pelayanan Bank Syariah kepada Usaha Mikro 1 MAPPING OF CONDITIONS AND POTENTIAL OF BMT : Partnership to Expand the Market and Linkage of Islamic Banking Services to the. Jurnal Al-Muzara'ah, I(1), (2013) : 1-18.

7 Adnan, M. A., \& Ajija, S. R., The effectiveness of Baitul Maal wat Tamwil in reducing poverty: The case of Indonesian Islamic Microfinance Institution. Humanomics, 31(2), (2015) : 160-182.

8 Rusydiana, A., \& Devi, A.. CHALLENGES IN DEVELOPING BAITUL MAAL WAT TAMWIIL ( BMT ) IN INDONESIA USING ANALYTIC NETWORK PROCESS (ANP) CHALLENGES IN DEVELOPING BAITUL MAAL WAT TAMWIIL ( BMT ) IN INDONESIA USING ANALYTIC NETWORK PROCESS ( ANP ). Business and Management Quarterly Review, 4(2), (2018) : 51-62.

9 (Apriadi \& Findi A, Solusi Peningkatan Sumberdaya Manusia Pada Baytul Maal wat Tamwil (BMT) di Indonesia Melalui Pendekatan Analytic Network Process ( ANP) The Solution of Human Resources Development for Baytul Maal wat Tamwil ( BMT ) in Indonesia : an Analytic Network Pr. Jurnal Al-Muzara'ah, 1(2), (2013) : 107-118 10 Sakti, A.. PEMETAAN KONDISI DAN POTENSI BMT : Kemitraan dalam rangka Memperluas Pasar \& Jangkauan Pelayanan Bank Syariah kepada Usaha Mikro 1 MAPPING OF CONDITIONS AND POTENTIAL OF BMT : Partnership to Expand the Market and Linkage of Islamic Banking Services to the. Jurnal Al-Muzara'ah, I (1), (2013) : 1-18 11 Masyithoh, (Masyithoh, Analisis Normatif Undang-undang No. 1 Tahun 2013 tentang Lembaga Keuangan Mikro (LKM) atas Status Badan Hukum dan Pengawasan Baitul Maal wat Tamwil (BMT). Economica Jurnal Ekonomi Islam, V(1), (2013): 17-36.
} 
Pemetaan Permasalahan BMT (Baitul Mal Wat Tamwil):

Pendekatan Teori Manajemen Strategi Environmental Scaning

memetakan permasalahan BMT dengan berlandaskan pada suatu teori tertentu. Penelitian ini bertujuan untuk memetakan permasalahan BMT dengan pendekatan teori manajemen strategi. Pertanyaan (question research) penelitian ini adalah bagaimanakah pemetaan permasalahan BMT dengan pendekatan manajemen strategi?

Perbedaan penelitian ini dibandingkan dengan penelitian sebelumnya adalah pada pengambilan fokus permasalahan. Penelitian ini fokus pada pemetaan permasalahan BMT. Penekanan bukan pada banyaknya detil inventarisasi permasalahan atau tingkat kepentingan permasalahan, tetapi pada sistematisasi pemetaan permasalahanan, karena hal itu belum menjadi perhatian peneliti sebelumnya.

Penelitian ini terinspirasi dari penelitian Mia, Lee, Chandran, Rasiah, \& Rahman tentang penerapan life cycle theory (LCT) pada pemodelan siklus pertumbuhan Lembaga Keuangan Mikro (LKM).12 Sistematisasi pemetaan permasalahan mendasarkan pada teori manajemen strategi, khususnya teori lingkungan makro perusahaan Thompson Jr. \& Strickland III,13 lingkungan industri atau lingkungan persaingan diadopsi dari teori five force Porter, ${ }^{14}$ dan lingkungan Internal menggunakan teori rantai nilai Porter. ${ }^{15}$ Penelitian ini diharapkan akan memetakan permasalahan BMT secara lebih komprehensif.

\section{METODOLOGI PENELITIAN}

Jenis penelitian ini adalah kualitatif. Penelitian ini bersifat deksriptif. Sumber data yang digunakan adalah sumber data sekunder berupa dokumen. Dokumen dibatasi berupa buku teks (textbook) dan jurnal ilmiah dengan kategori tertentu. ${ }^{16}$

Kategori jurnal meliputi keterkaitan dengan level indeks jurnal, tema dan tahun terbit. Kategori jurnal internasional yang digunakan adalah yang terindeks scopus. Berbagai jurnal terbitan dari penerbit Taylor and Francis Group, Elsevier, Springer, Emerald, IGI Global, Wiley dan lainnya harus dikonfirmasi ke Scimago untuk mengetahui indek scopus. Jurnal dari penerbit dalam negeri juga dikonfirmasi ke Sinta Dikti untuk mengetahui indeks Sinta. Kategori jurnal dalam negeri yang digunakan sebagai data dokumen untuk diteliti minimal terkategori Sinta 3.

\footnotetext{
12 Mia, M. A., Lee, H. A., Chandran, V., Rasiah, R., \& Rahman, M., History of microfinance in Bangladesh: A life cycle theory approach. Business History, 6791, (2017) : 1-31

13 Thompson Jr., A. A., \& Strickland III, A. J., Startagic Management, Concepts and Case. Boston: McGraw-Hill Higher Education, (2003), p. 74

14 Porter, M. E., COMPETITIVE STRATEGY, 1(2), (1980) : 12-17.

15 Porter, M. E., Towards a Dynamic Theory of Strategy, 12, (1991) : 95-117.

16 Satori, D., \& Komariah, A., Metodologi penelitian kualitatif. Bandung: Alfabeta, 145-160
} 
Gambar 1.

Prosedur Analisa Konten Kualitatif 17

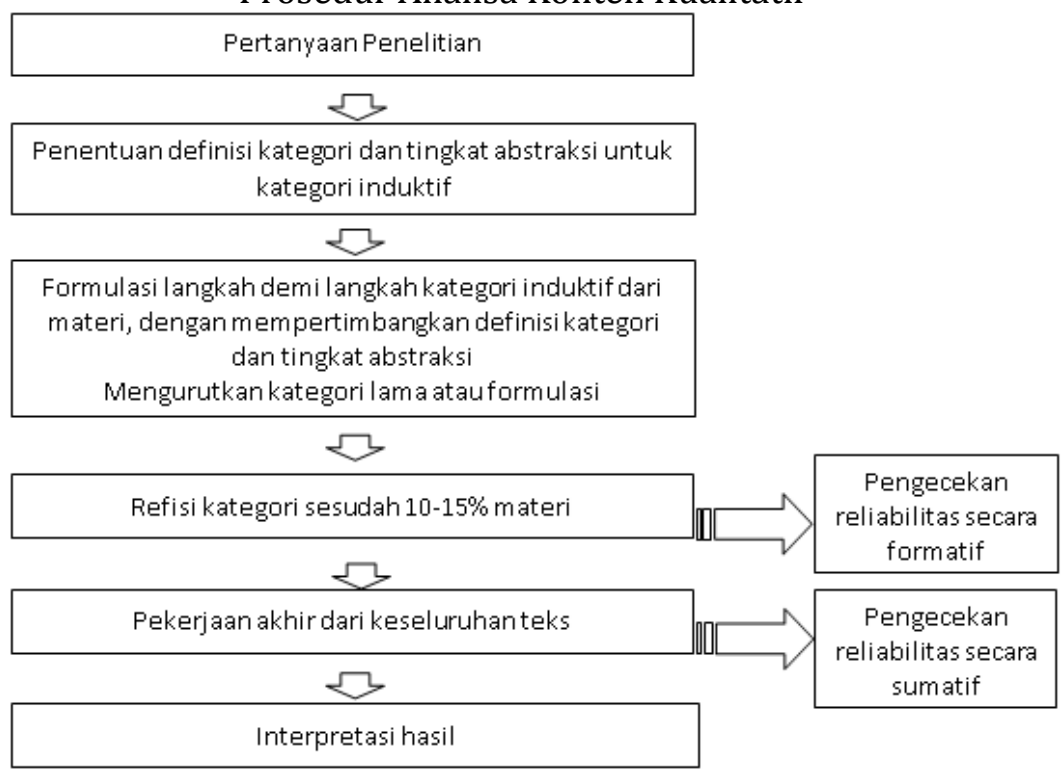

Kategori kedua, berdasarkan relevansi tema kajian jurnal. Tema kajian yang digunakan adalah tentang Islamic microfinance BMT (Islamic microfinance, microfinance, perbankan Syariah dan small medium entrepreneurships, SMEs), manajemen strategi (lingkungan perusahaan, environmental scanning), dan metodologi kualitatif (kualitatif, studi literatur). Kategori ketiga berkaitan dengan tahun publikasi. Tahun publikasi diutamakan lima tahun terakhir. Publikasi di atas lima tahun tetap bisa digunakan jika relevansi temanya erat (penting) atau jurnal terbaru yang berkaitan dengan tema sulit dicari.

Kategori buku nya berkaitan dengan tema teori dan metodologi. Kategori buku yang berkaitan dengan teori manajemen strategi adalah penulis internasional (berbahasa Inggris atau terjemahan berbahasa Indonesia). Kategori buku yang terbitan yang berkaitan dengan metodologi lebih dilihat dari segi relevansi dengan metoda kualitatif studi kepustakaan.

Teknik pelaksanaan pengumpulan data jurnal internasional diawali pencarian melalui web-web publisher penerbit: Taylor and Francis Group, Elsevier, Springer, Emerald, IGI Global, Wiley dan lainnya. Jurnal dalam negeri dicari melalui web Sinta Dikti dilanjutkan ke web penerbit jurnal. Cara lainnya adalah melalui mesin pencari Google Scholar. Penyiapan buku pustaka dilakukan secara manual. Buku-buku yang berkaitan dengan teori dipilih yang dihasilkan penulis internasional, sedangkan buku-buku yang berkaitan dengan metodologi dipilih yang memuat metode kualitatif.

Tahap pengecekan jurnal dilakukan dengan mengkonfirmasikan nama jurnal ke Scimago untuk jurnal internasional dan Sinta Dikti untuk jurnal dalam negeri, Pengecekan jurnal selanjutnya melalui relevansi judul, abstrak dan hasil penelitian. Pengecekan buku yang berkaitan dengan teori dengan membaca dan mencocokkan modelnya.

Tahap akhir berupa kajian serius terhadap kredibilitas dan konten jurnal. Kredibilitas jurnal dilakukan dengan mengkonfirmasi ulang setiap jurnal melalui Scimago dan Sinta, untuk menghindari kesalahan. Pengujian relevandsi konten jurnal dan buku dilakukan dengan melakukan review. Poin-poin penting dicatat sebagai bahan penulisan dalam bentuk

17 Ibid. 
Pemetaan Permasalahan BMT (Baitul Mal Wat Tamwil):

tulisan jurnal ilmiah. Analisa terhadap data-data permasalahan BMT menggunakan kaidah Analisa penelitian kualitatif.

Tahapan analisa penelitian kualitatif meliputi reduksi, penyajian dan konklusiverifikasi.18 Proses koleksi data dilakukan dengan melakukan kajian terhadap terkait permasalahan BMT yang bersumber dari jurnal terseleksi. Data permasalahan BMT yang terkoleksi disajikan dalam tabel sementara. Proses reduksi data dilakukan dengan menggabungkan beberapa permasalahan menjadi satu kategori berdasarkan kepada kedekatan permasalahan sehingga terformulasikan menjadi lebih sederhana. Data yang sudah mengalami reduksi selanjutnya ditabelkan untuk dilakukan konklusi-verifikasi, sebagaimana Gambar 2.

Gambar 2

Analisis Data Kualitatif Model Miles Hubberman ${ }^{19}$

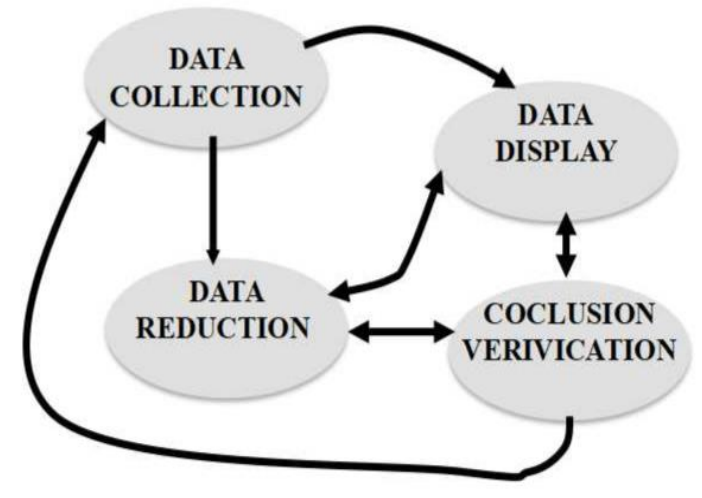

\section{Pengumpulan Data dan Analisis}

Tahap pertama adalah perunutan literatur. Perunutan literatur pada tahap pertama belum ketat fokusnya, baik dari segi tema, tahun, indeks jurnal, penerbit, maupun mesin pencari online yang digunakan. Literatur dirunut menggunakan mesin pencari google scholar dan situs penerbit jurnal seperti emerald, elsevier, taylor \& frnacis, springer, sage dan wiley. Penelusuran tahap pertama menghasilkan 53 literatur.

Tahap kedua, reduksi data. Tahap selanjutnya sudah semakin mengerucut dengan penerapan kategori yang semakin ketat. Tahap kedua dilakukan reduksi menggunakan standar kualitas jurnal. Jurnal internasional menggunakan standar minimal schimago rangking 4. Sedangkan jurnal nasional menggunakan standar Sinta, minimal terkategori Sinta 3.

18 Sugiyono. (2018). Metode Penelitian Manajemen. Bandung: Alfabeta, 400 - 429
19 ibid 
Tabel 1.

Penyajian Hasil Reduksi Data

\begin{tabular}{|c|c|c|}
\hline No & Data Permasalahan BMT & Nara Sumber Penulis Jurnal \\
\hline 1 & $\begin{array}{l}\text { Otoritas (regulasi, } \\
\text { dukungan, pengawasan) }\end{array}$ & $\begin{array}{l}\text { (Masyithoh, 2013; Sakti, 2013) } \\
\text { (Apriadi \& Findi, 2013; Karsidi } \\
\text { dkk., 2011, Riwajanti, 2014) }\end{array}$ \\
\hline 2 & Infrastruktur pendukung & (Sakti, 2013) \\
\hline 3 & SDM & $\begin{array}{l}\text { (Apriadi \& Findi, 2013; Karsidi } \\
\text { dkk., 2011; Sakti, 2013; } \\
\text { Susilowati, 2018; Trimulato, } \\
\text { 2018) }\end{array}$ \\
\hline 4 & Teknis pengelolaan & $\begin{array}{l}\text { (Apriadi \& Findi, 2013; Karsidi } \\
\text { dkk., 2011) }\end{array}$ \\
\hline 5 & Keterbatasan modal & (Sakti, 2013) \\
\hline 6 & $\begin{array}{l}\text { Internal BMT, rasa } \\
\text { memiliki }\end{array}$ & (Apriadi \& Findi, 2013) \\
\hline 7 & $\begin{array}{l}\text { Ambivalensi konsep } \\
\text { syariah }\end{array}$ & (Karsidi dkk., 2011) \\
\hline 8 & Masyarakat & (Apriadi, 2013; Sakti, 2013) \\
\hline 9 & Pembiayaan alternative & (Apriadi \& Findi, 2013) \\
\hline
\end{tabular}

Pada tahap ketiga dilakukan review terhadap jurnal-jurnal kunci dan pada sebagian jurnal pendukung. Catatan-catatan penting yang didapatkan dari proses review jurnal, kemudian dikaji dengan mengacu kepada beberapa teori dalam manajemen strategi. Catatan hasil review tersebut mengarahkan kepada pengelompokan jurnal. Kelompok jurnal pertama diposisikan sebagai bahan penguatan latar belakang masalah. Kelompok jurnal kedua dipakai sebagai acuan pendukung penyusunan model. Kelompok jurnal ketiga sebagai sumber data sekunder sebagai bahan pemetaan permasalahan. Kelompok jurnal keempat sebagai acuan pendukung metodologi. Kelompok jurnal kelima cadangan untuk digunakan sebagai pengkayaan sesuai kebutuhan. Adapun textbook terbagi dua. Kelompok pertama sebagai sumber utama acuan model dan kelompok kedua sebagai acuan utama metodologi.

\section{Konsklusi dan verifikasi data}

Jurnal-jurnal yang akan ditampilkan pada pembahasan ini adalah jurnal kelompok ketiga, untuk mendapatkan data-data sekunder permasalahan BMT. Langkah penyajian dan reduksi data dilakukan dengan mendasarkan kepada kedekatan permasalahan. Hasil reduksi data ditampilkan pada pada Tabel 1.

\section{HASIL DAN PEMBAHASAN}

\section{Permasalahan Lingkungan Internal.}

Permasalahan lingkungan internal meliputi SDM, teknis pengelolaan, rasa memiliki, dan keterbatasan modal. Permasalahan dengan pendekatan fungsi organisasi ${ }^{20}$ terlihat bahwa permasalahan ada pada SDM dan permodalan. SDM mempunyai berbagai permasalahan yang kompleks. penerapan manajemen sumber daya Islami (MSDM Islami)

\footnotetext{
${ }^{20}$ Hunger, J. D., \& Wheelen, T. L., Manajemen Strategis. Yogyakarta: Penerbit Andi (2003)
} 
Pemetaan Permasalahan BMT (Baitul Mal Wat Tamwil):

Pendekatan Teori Manajemen Strategi Environmental Scaning

pada setiap tahapan proses Manajemen SDM untuk menyiapkan SDM unggul.21 Dukungan pemanfaatan system informasi kepegawaian (Simpeg) juga penting dalam perencanaan, staffing, pengembangan SDM dan hubungan kepegawaian. ${ }^{22}$ Upaya (upgrade) untuk memaksimalkan peran SDM dalam melakukan pendekatan terhadap calon nasabah, ${ }^{23}$ terlebih didukung dengan keunggulan SDM yang memahami ilmu ekonomi dan ilmu syariah. ${ }^{24}$

Permasalahan internal lainnya adalah menyangkut ambivalensi konsep konsep Syariah pada produk jasa keuangan Syariah BMT. Permasalahan ini krusial bagi BMT karena menyangkut core value yang ditawarkan kepada masyarakat sebagai konsumen, diantaranya terdapat ambivalensi antara konsep Syariah yang telah disepakati dengan operasionalisasinya, ${ }^{25}$ serta adanya ketidaksyariahan dalam simpan pinjam, pembiayaan, kesiapan menanggung kerugian dan pada substansi akad-akad. ${ }^{26}$

\section{Permasalahan Lingkungan Industri}

Permasalahan pada level lingkungan industri adalah pada persepsi masyarakat. Persepsi masyarakat bisa dikaitkan dengan ambivalensi konsep Syariah, yang bisa menurunkan kepercayaan masyarakat/nasabah. ${ }^{27} \mathrm{Hal}$ ini sebagaimana penelitian Khan \& Akhter, bahwa kepuasan konsumen terhadap Lembaga keuangan mikro Syariah (Islamic microfinance) dimoderasi oleh persepsi Syariah.28 Ketidakpuasan masyarakat ataupun persepsi masyarakat terkait ambivalensi Syariah bisa menjadikan masyarakat menganggap sama antara Lembaga keuangan mikro Syariah dengan Lembaga pembiayaan alternative konvensional, sehingga memunculkan persaingan. Hal ini menyebabkan kurangnya kepercayaan dari para nasabah. Permasalahan lingkungan makro.

Permasalahan Otoritas (regulasi, dukungan, pengawasan) dan infrastruktur pendukung menunjukkan hambatan lingkungan makro, yang dalam pendekatan teori Thompson Jr. \& Strickland III ${ }^{29}$ adalah pada bidang legislasi dan regulasi. Dari penelitian sederhana ini didapatkan permasalahan BMT adalah pada SDM (internal), konsep produk jasa (internal), persepsi masyarakat tentang kesyariahan BMT (daya tawar konsumen) dan legislasi dan regulasi (masalah makro).

\footnotetext{
21 Trimulato, Manajemen Sumber Daya Manusia Islam Bagi SDM di Bank Syariah. Iqtishadia Jurnal Ekonomi Dan Perbankan Syariah, 5(2), (2018): 238-265.

22 Wijiharta, Analisis Pemanfaatan Sistem Informasi Kepegawaian Pada Manajemen Kepegawaian: Studi Kasus Pada STEI Hamfara Yogyakarta. MUKADDIMAH: Jurnal Studi Islam, 2(1), (2017): 115-126

23 Susilowati, L, Model Strategi Tumbuh Dan Bertahan Pada Pengelolaan Baitul Maal Wat Tamwil (BMT) Di Kabupaten Tulungagung Dan Ponorogo. Iqtishadia Jurnal Ekonomi Dan Perbankan Syariah, 5(2), (2018): 163-187.

24 Trimulato, Manajemen Sumber Daya Manusia Islam Bagi SDM di Bank Syariah. Iqtishadia Jurnal Ekonomi Dan Perbankan Syariah, 5(2), (2018): 238-265

25 Karsidi, Rahab, \& Mustofa, R. (2011). Strategi peningkatan profesionalisme praktisi baitul maal wat tamwil (bmt) di kabupaten banyumas. PERFORMANCE, 14(2), 13-34.

${ }^{26}$ Fidiana. (2017). Tinjauan kritis kesyariahan koperasi syariah. Iqtishadia Jurnal Ekonomi Dan Perbankan Syariah, 4(2), 138-154.

27 Karsidi, Rahab, \& Mustofa, R. (2011). Strategi peningkatan profesionalisme praktisi baitul maal wat tamwil (bmt) di kabupaten banyumas. PERFORMANCE, 14(2), 13-34.

${ }^{28}$ Khan, S., \& Akhter, W. (2017). Service quality and the moderating effect of Shari'ah perception on client satisfaction: A comparison of islamic and conventional microfinance in Pakistan. Cogent Economics and Finance, $5(1), 1-20$.

29 Thompson Jr., A. A., \& Strickland III, A. J. (2003). Startagic Management, Concepts and Case. Boston: McGraw-Hill Higher Education
} 


\section{Gambar 2}

Peta Permasalahan BMT Berdasarkan Teori Environmental Scanning
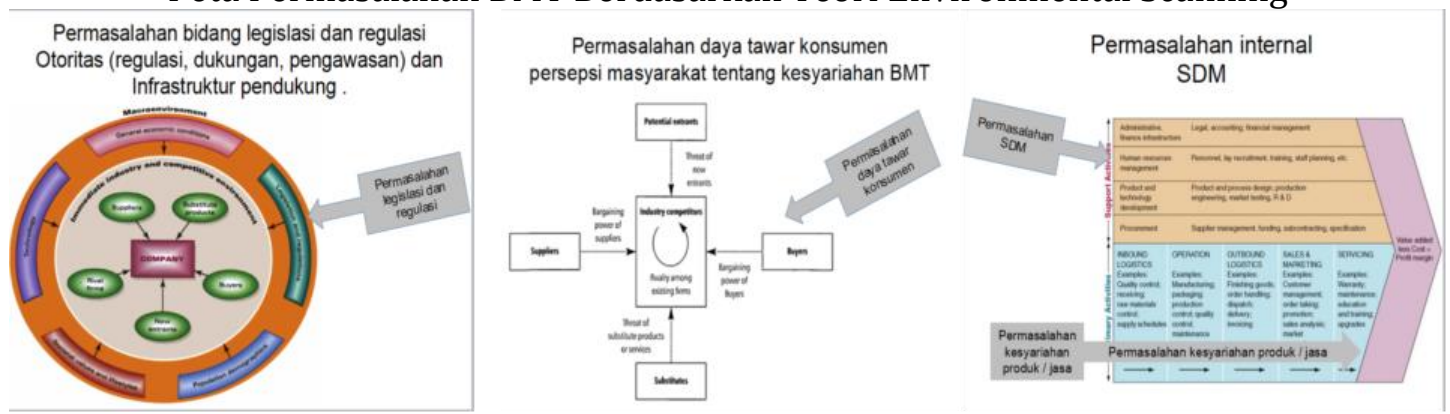

Permasalahan BMT sebagaimana yang di Tabel 1, jika dilakukan pemetaan dengan mendasarkan pada teori manajemen strategi (Gambar 1 dan Gambar 2) adalah sebagaimana pada gambar 6. Peta permasalahan tergambar lebih komprehensif pada Gambar 3.

\section{Gambar 3}

Peta komprehensif Permasalahan BMT.30

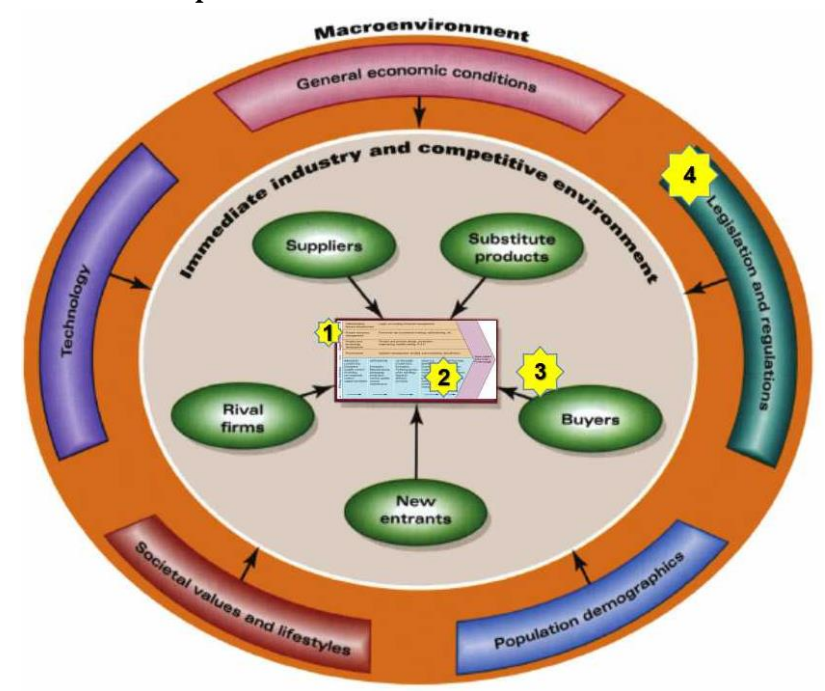

Penyimpulan tersebut menunjukkan bahwa pemetaan permasalahan BMT menggunakan teori environmental scanning, sebagai salah satu konsep pada manajemen strategi, bisa diterapkan. Sebagaimana penerapan life cycle theory (LCT) pada pemodelan siklus pertumbuhan Lembaga keuangan mikro. ${ }^{31}$

\section{PENUTUP}

Kesimpulan pertama, bahwa pemetaan permasalahan BMT menggunakan teori environmental scanning manajemen strategi bisa diterapkan. Kesimpulan kedua tentang peta permasalahan lingkungan internal BMT adalah pada SDM dan konsep produk jasa,

30 Thompson Jr., A. A., \& Strickland III, A. J. (2003). Startagic Management, Concepts and Case. Boston: McGraw-Hill Higher Education

31 Mia, M. A., Lee, H. A., Chandran, V., Rasiah, R., \& Rahman, M. (2017). History of microfinance in Bangladesh: A life cycle theory approach. Business History, 6791, 1-31 
Pemetaan Permasalahan BMT (Baitul Mal Wat Tamwil):

Pendekatan Teori Manajemen Strategi Environmental Scaning

permasalahan lingkungan industry adalah pada daya tawar konsumen/nasabah (penerimaan masyarakat), dan permasalahan lingkungan makro BMT adalah legislasi dan regulasi.

\section{DAFTAR PUSTAKA}

Adnan, M. A., \& Ajija, S. R. (2015). The effectiveness of Baitul Maal wat Tamwil in reducing poverty: The case of Indonesian Islamic Microfinance Institution. Humanomics, 31(2), 160-182. https://doi.org/http://dx.doi.org/10.1108/H-03-2012-0003

Apriadi, F., \& Findi A, M. (2013). Solusi Peningkatan Sumberdaya Manusia Pada Baytul Maal wat Tamwil ( BMT ) di Indonesia Melalui Pendekatan Analytic Network Process ( ANP ) The Solution of Human Resources Development for Baytul Maal wat Tamwil ( BMT ) in Indonesia : an Analytic Network Pr. Jurnal Al-Muzara'ah, 1(2), 107-118.

David, F. R. (2008). Manajemen Strategis. Jakarta: Salemba Empat.

Fadllan, Fadllan, dan Syafi'i Syafi'i. "IMPLEMENTASI PRODUK TABUNGAN UMUM SYARIAH DI KJKS BMT UGT SIDOGIRI CABANG PEMBANTU TLANAKAN PAMEKASAN." IQTISHADIA: Jurnal Ekonomi \& Perbankan Syariah 2, no. 2 (2015): 171-190.

Fidiana. (2017). Tinjauan kritis kesyariahan koperasi syariah. Iqtishadia Jurnal Ekonomi Dan Perbankan Syariah, 4(2), 138-154.

Hunger, J. D., \& Wheelen, T. L. (2003). Manajemen Strategis. Yogyakarta: Penerbit Andi.

Karsidi, Rahab, \& Mustofa, R. (2011). Strategi peningkatan profesionalisme praktisi baitul maal wat tamwil (bmt) di kabupaten banyumas. PERFORMANCE, 14(2), 13-34.

Khan, S., \& Akhter, W. (2017). Service quality and the moderating effect of Shari'ah perception on client satisfaction: A comparison of islamic and conventional microfinance in Pakistan. Cogent Economics and Finance, 5(1), 1-20. https://doi.org/10.1080/23322039.2017.1315206

Liñares-zegarra, J., \& Wilson, J. (2017). The size and growth of microfinance institutions. The British Accounting Review. https://doi.org/10.1016/j.bar.2017.11.006

Masyithoh, N. D. (2013). ANALISIS NORMATIF UNDANG-UNDANG NO. 1 TAHUN 2013 TENTANG LEMBAGA KEUANGAN MIKRO (LKM) ATAS STATUS BADAN HUKUM DAN PENGAWASAN BAITUL MAAL WAT TAMWIL (BMT). Economica Jurnal Ekonomi Islam, $V(1), 17-36$.

Mia, M. A., Lee, H. A., Chandran, V., Rasiah, R., \& Rahman, M. (2017). History of microfinance in Bangladesh: A life cycle theory approach. Business History, 6791, 1-31. https://doi.org/10.1080/00076791.2017.1413096

Mobin, M. A., Masih, M., \& Alhabshi, S. O. (2017). Religion of Islam and Microfinance: Does It Make Any Difference? Emerging Markets Finance and Trade, (January), 1-33. https://doi.org/10.1080/1540496X.2016.1268526

Porter, M. E. (1980). COMPETITIVE STRATEGY, 1(2), 12-17.

Porter, M. E. (1991). Towards a Dynamic Theory of Strategy, 12, 95-117.

Rusydiana, A., \& Devi, A. (2018). CHALLENGES IN DEVELOPING BAITUL MAAL WAT TAMWIIL ( BMT ) IN INDONESIA USING ANALYTIC NETWORK PROCESS ( ANP ) CHALLENGES IN DEVELOPING BAITUL MAAL WAT TAMWIIL ( BMT ) IN INDONESIA USING ANALYTIC NETWORK PROCESS ( ANP ). Business and Management Quarterly Review, 4(2), 51-62.

Sakti, A. (2013). PEMETAAN KONDISI DAN POTENSI BMT: Kemitraan dalam rangka Memperluas Pasar \& Jangkauan Pelayanan Bank Syariah kepada Usaha Mikro 1 MAPPING OF CONDITIONS AND POTENTIAL OF BMT: Partnership to Expand the Market and Linkage of Islamic Banking Services to the. Jurnal Al-Muzara'ah, I(1), 118. 
Wijiharta

Satori, D., \& Komariah, A. (2014). Metodologi penelitian kualitatif. Bandung: Alfabeta.

Sugiyono. (2018). Metode Penelitian Manajemen. Bandung: Alfabeta.

Susilowati, L. (2018). Model Strategi Tumbuh Dan Bertahan Pada Pengelolaan Baitul Maal Wat Tamwil (BMT) Di Kabupaten Tulungagung Dan Ponorogo. Iqtishadia Jurnal Ekonomi Dan Perbankan Syariah, 5(2), 163-187. https://doi.org/10.19105/iqtishadia.v5i2.1891

Thompson Jr., A. A., \& Strickland III, A. J. (2003). Startagic Management, Concepts and Case. Boston: McGraw-Hill Higher Education.

Trimulato. (2018). Manajemen Sumber Daya Manusia Islam Bagi SDM di Bank Syariah. Iqtishadia Jurnal Ekonomi Dan Perbankan Syariah, 5(2), 238-265. https://doi.org/10.19105/iqtishadia.v5i2.1627

Wijiharta. (2017). Analisis Pemanfaatan Sistem Informasi Kepegawaian Pada Manajemen Kepegawaian: Studi Kasus Pada STEI Hamfara Yogyakarta. MUKADDIMAH: Jurnal Studi Islam, 2(1), 115-126.

Wulandari, P., Liyu, S. K., Sulung, A., Iwani, N., \& Putri, S. (2016). Unique aspects of Islamic microfinance financing process: experience of Baitul Maal Wa Tamwil in Indonesia. Humanomics, 32(3), 1-19. https://doi.org/http://dx.doi.org/10.1108/H-09-20140062 